\title{
Risk Early Warning Analysis on Vulnerability of Metro Stampede Accident
}

\author{
Wang Qi-quan, Zhu Qian-kun \\ Department of Safety Engineering, China University of Labor Relations, Beijing, China
}

Email address:

wqq_100@163.com(Wang Qi-quan)

To cite this article:

Wang Qi-quan, Zhu Qian-kun. Risk Early Warning Analysis on Vulnerability of Metro Stampede Accident. Advances in Applied Sciences. Vol. 3, No. 2, 2018, pp. 9-18. doi: 10.11648/j.aas.20180302.11

Received: March 21, 2018; Accepted: April 2, 2018; Published: May 5, 2018

\begin{abstract}
Based on the statistical analysis of the typical crowded stampede in the past ten years and based on the theory of vulnerability, determine the vulnerable parts of the crowded stampede in the subway station crowd, combined with interpretative structural model, systematically analyze the fragile parts of the crowded stampede at the subway station and find out the relationship between the vulnerable points and establish a multi-level hierarchical subway stampede Structural model. The generality of the characteristics of the Beijing subway crowd was calculated by setting up observation points for escalators and stairways at five high-speed subway stations, use Matlab and Spss to calculate the regression equation, and determine the related relationship between traffic flow, speed and crowd flow and crowded stampede, construct the metro crowding stampede accident risk matrix and put forward different levels of risk warning control measures.
\end{abstract}

Keywords: Crowded Stampede, Vulnerability Analysis, Interpretive Structure Model, Risk Early Warning

\section{Introductions}

Due to the complexity and particular characters of the city metro system, consequences often tend to be disastrous when accident occurred. According to incomplete statistics, more than $60 \%$ of the accidents occurred during metro operation hours [1]. Main types of accident occurring in metro system are usually overcrowding and stampede, therefore conducting risk analysis on the vulnerability of metro accidents will help prevent overcrowding and stampede happening in the metro station.

Given the fact that passenger flow density in metro systems outside China rarely reaches the congested state, researches on metro accidents therefore are mainly focus on emergency response of terrorist attacks and violent incidents [2] as well as safety management. Those researches however are focused on large-scale activities, parades and similar scenarios [3], hence blanks are still existed in the field of studying overcrowding metro station specifically and systematically.

In China, researcher tend to apply classical risk theory to study over overcrowding and stampede [4]; Zhang Qingsong [5] constructed a formula to express risks of overcrowding and stampede based on previous studies; Wang Qiquan [6] studied the potential location and triggering factors of metro overcrowding and stampede accident by statistic analysis and establishing quantitative analysis model, it helped to lay the foundations of the research for metro overcrowding and stampede; Liu Yan, Wang Tong, etc., [7] based on the previous studies of Wang Qiquan used the DEA (Date Envelopment Analysis) model to assess the threats of metro overcrowding and stampede accident successfully, which provides a new method of risk assessment of metro overcrowding and stampede accident. However, in DEA model, monotony of selections of input and output index as well as weight factors still exists, hence improvement is further needed. Given the fact, studies over overcrowding and stampede in China are still concentrating on reliable analysis [8] and risk assessment, occurring mechanism of stampede accident, the relations between influential variables as well as vulnerability analysis are hence to be studies further. [9]

Based on the researches mentioned, the author will start by vulnerability analysis, combining data from previous studies, use the theory of causes of metro accidents, the vulnerability theory and the interpretive structural models to determine the potential relations between various vulnerable locations with structural complexity and establish a multilevel hierarchical structural model, use the trace intersecting theory considering factors like human factors (people's unsafe behaviors) and 
material factors (unsafe status of matters) and multiple environmental variables to perform qualitative analysis and reveal the relations between factors as well as occurring mechanism of metro accidents in order to further establish metro stampede risk assessment matrix, propose advisory precautions and provide a scientific basis and treatments to prevent metro overcrowding and stampede accident.

\section{Analysis of Vulnerability Factors of Subway Crowded Stampede}

\subsection{Analysis on Influence Factors of Subway Crowded Stampede}

During the analysis of the reproduction of a typical subway stampede accident, it is determined that the subway stampede can't be separated from the four elements of human-machine-environment-management. According to the theory of accident risk in risk control theory, this paper analyzes the influencing factors of subway vulnerability. Taking the "vulnerability" in subway system as the research center, starting from the four factors of personnel, equipment, environment and management, besides the 10 typical subway stampede accidents from 2008 to 2015 , this paper combines the various factors of stampede of large-scale activities, combines the influence of personnel, equipment, environment and management on the vulnerability of the subway and adopts the fuzzy Delphi method to sum up Table 1 shows the initial factors for the vulnerability of a subway stampede, uses fuzzy Delphi method to summarize the initial factors of the vulnerability of subway crowded stampede, as shown in Table 1.

Table 1. Initial factors on the vulnerability of subway crowded stampede.

\begin{tabular}{llll}
\hline Personnel factors & Specific performance & Equipment factors & Specific performance \\
\hline H1 & Peak duration & F1 & Equipment position \\
H2 & Peak passenger flow density & F2 & Equipment load \\
H3 & Escalator on-board time & F3 & Number of disease equipment \\
H4 & Walking speed & F4 & Equipment performance integrity \\
H5 & Proportion of floating population & F6 & Misoperation recovery ability \\
H6 & Psychological diathesis & & Equipment stability \\
H7 & Physiologic quality & Management factors & Specific performance \\
Environmental factors & Specific performance & M1 & Emergency command ability of emergency \\
E1 & Rationality of design & Evacuation rehearsal \\
E2 & Effectiveness of passenger flow diversion facilities & M2 & Measures to deal with the large passenger flow \\
E3 & The quickness of accident evacuation & M3 & . \\
\hline
\end{tabular}

\subsection{Construct the Interpretation Structure Model of Subway Crowded Stampede (ISM)}

\subsubsection{Organize a Team that Implements the Interpretive Structural Model (ISM)}

The team is generally composed of coordinators, technical experts in methods, and participants. The team consists of five members, each person should have a certain background of expertise and the team leader should be the decision-maker.

\subsubsection{Set Subway Congestion Stampede Impact Factors}

The problem of this study is to analyze the influencing factors of the vulnerability of the stampede in subway in the previous part. The model is established to make a qualitative analysis, and a multi-level hierarchical structural model is established to integrate the vulnerability factor system into it.

\subsubsection{Establish the Leading Factors of the Subway Crowded Stampede}

The members of the group need to decide the specific contents of the direct indirect factors that lead to the accident according to the causes of the accident, the casualties and the place where the subway was stampeded in recent ten years in Beijing.

\subsubsection{Enumerate the Correlation of the Influencing Factors of the Subway Stampede Accident, Build Reachable Matrix}

According to the mutual influence of the vulnerability factors of subway stampede accidents, build a directed connection diagram of subway vulnerability factors and build an adjacency matrix $A$. Then add a unit matrix $I$ to the adjacency matrix $\mathrm{A}$, and after the calculation, the reachable matrix AI1 is get with the length less than or equal to 1 between the nodes; Suppose the matrix $\mathrm{AI} 2=(\mathrm{A}+\mathrm{I})^{2}{ }^{2}$ is $\mathrm{AI}^{2}$, which is calculated using Boolean algebraic operation rules to obtain a matrix AI2, which represents the reach ability of paths between nodes with length less than or equal to 2 . The 18 factors in this system belong to a major system, so defining $\operatorname{AI}\left(n_{i}\right)$ as the set of variables that can be reached by variable $i$, that is reachable set; $R\left(n_{i}\right)$ is used to represent a set of variables that can reach the variable $\mathrm{I}$, which is a set of antecedent set. The accessibility is shown in Table 2 according to the adjacency matrix R.

Table 2. Reachability matrix analysis table for subway crowded stampede.

\begin{tabular}{|c|c|c|c|c|c|c|c|c|c|c|c|c|c|c|c|c|c|c|}
\hline & H1 & $\mathrm{H} 2$ & H3 & H4 & H5 & H6 & H7 & F1 & F2 & F3 & F4 & F5 & F6 & E1 & E2 & E3 & M1 & M2 \\
\hline H1 & 0 & 1 & 1 & 0 & 0 & 0 & 0 & 0 & 0 & 0 & 1 & 0 & 0 & 0 & 0 & 0 & 0 & 0 \\
\hline $\mathrm{H} 2$ & 0 & 0 & 0 & 1 & 1 & 0 & 0 & 0 & 0 & 0 & 1 & 0 & 0 & 1 & 0 & 0 & 0 & 1 \\
\hline H3 & 0 & 0 & 0 & 1 & 0 & 0 & 0 & 0 & 0 & 0 & 1 & 0 & 0 & 0 & 0 & 0 & 0 & 0 \\
\hline H4 & 0 & 0 & 1 & 0 & 0 & 0 & 0 & 0 & 0 & 0 & 1 & 0 & 0 & 1 & 0 & 0 & 0 & 0 \\
\hline
\end{tabular}




\begin{tabular}{|c|c|c|c|c|c|c|c|c|c|c|c|c|c|c|c|c|c|c|}
\hline & H1 & H2 & H3 & H4 & H5 & H6 & H7 & F1 & F2 & F3 & F4 & F5 & F6 & E1 & E2 & E3 & M1 & M2 \\
\hline H5 & 0 & 0 & 1 & 1 & 0 & 0 & 0 & 0 & 0 & 0 & 0 & 0 & 0 & 0 & 1 & 1 & 0 & 1 \\
\hline H6 & 0 & 0 & 0 & 0 & 0 & 0 & 0 & 0 & 0 & 0 & 0 & 0 & 0 & 1 & 1 & 1 & 1 & 1 \\
\hline H7 & 1 & 0 & 0 & 1 & 0 & 0 & 0 & 0 & 0 & 0 & 0 & 0 & 0 & 1 & 1 & 1 & 1 & 1 \\
\hline F1 & 1 & 1 & 0 & 1 & 1 & 0 & 0 & 0 & 0 & 0 & 0 & 0 & 0 & 1 & 1 & 1 & 1 & 1 \\
\hline F2 & 0 & 0 & 0 & 0 & 0 & 0 & 0 & 0 & 0 & 1 & 1 & 1 & 0 & 0 & 0 & 1 & 0 & 0 \\
\hline F3 & 0 & 0 & 0 & 0 & 0 & 0 & 0 & 0 & 0 & 0 & 1 & 1 & 0 & 1 & 1 & 1 & 1 & 1 \\
\hline F4 & 0 & 0 & 0 & 0 & 0 & 0 & 0 & 0 & 1 & 1 & 0 & 1 & 0 & 0 & 1 & 1 & 1 & 1 \\
\hline F5 & 0 & 0 & 1 & 0 & 0 & 0 & 0 & 0 & 0 & 1 & 1 & 0 & 0 & 0 & 1 & 1 & 0 & 1 \\
\hline F6 & 0 & 0 & 0 & 0 & 0 & 0 & 0 & 1 & 1 & 1 & 1 & 1 & 0 & 0 & 1 & 1 & 1 & 1 \\
\hline E1 & 1 & 0 & 0 & 1 & 0 & 0 & 0 & 0 & 0 & 0 & 0 & 0 & 0 & 0 & 1 & 1 & 1 & 1 \\
\hline E2 & 0 & 0 & 0 & 1 & 0 & 0 & 0 & 0 & 0 & 0 & 0 & 0 & 0 & 0 & 0 & 1 & 1 & 1 \\
\hline E3 & 0 & 0 & 0 & 1 & 0 & 0 & 0 & 0 & 0 & 0 & 0 & 0 & 0 & 0 & 0 & 0 & 1 & 1 \\
\hline M1 & 0 & 0 & 0 & 0 & 0 & 0 & 0 & 0 & 0 & 0 & 0 & 0 & 0 & 1 & 0 & 1 & 0 & 1 \\
\hline M2 & 0 & 0 & 0 & 0 & 0 & 0 & 0 & 0 & 0 & 0 & 0 & 0 & 0 & 1 & 1 & 1 & 1 & 0 \\
\hline
\end{tabular}

\subsubsection{Decompose the Reach Ability Matrix, Build the Structure Model and Build the Interpretation Structure Model of the} Subway Crowded Stampede Accident

The adjacency matrix is used for loop analysis of the system so as to obtain a new order, and then use the self-multiplication method to obtain the reach ability matrix. The data are analyzed by the computer and the skeletal map is drawn as shown in Figure 1.

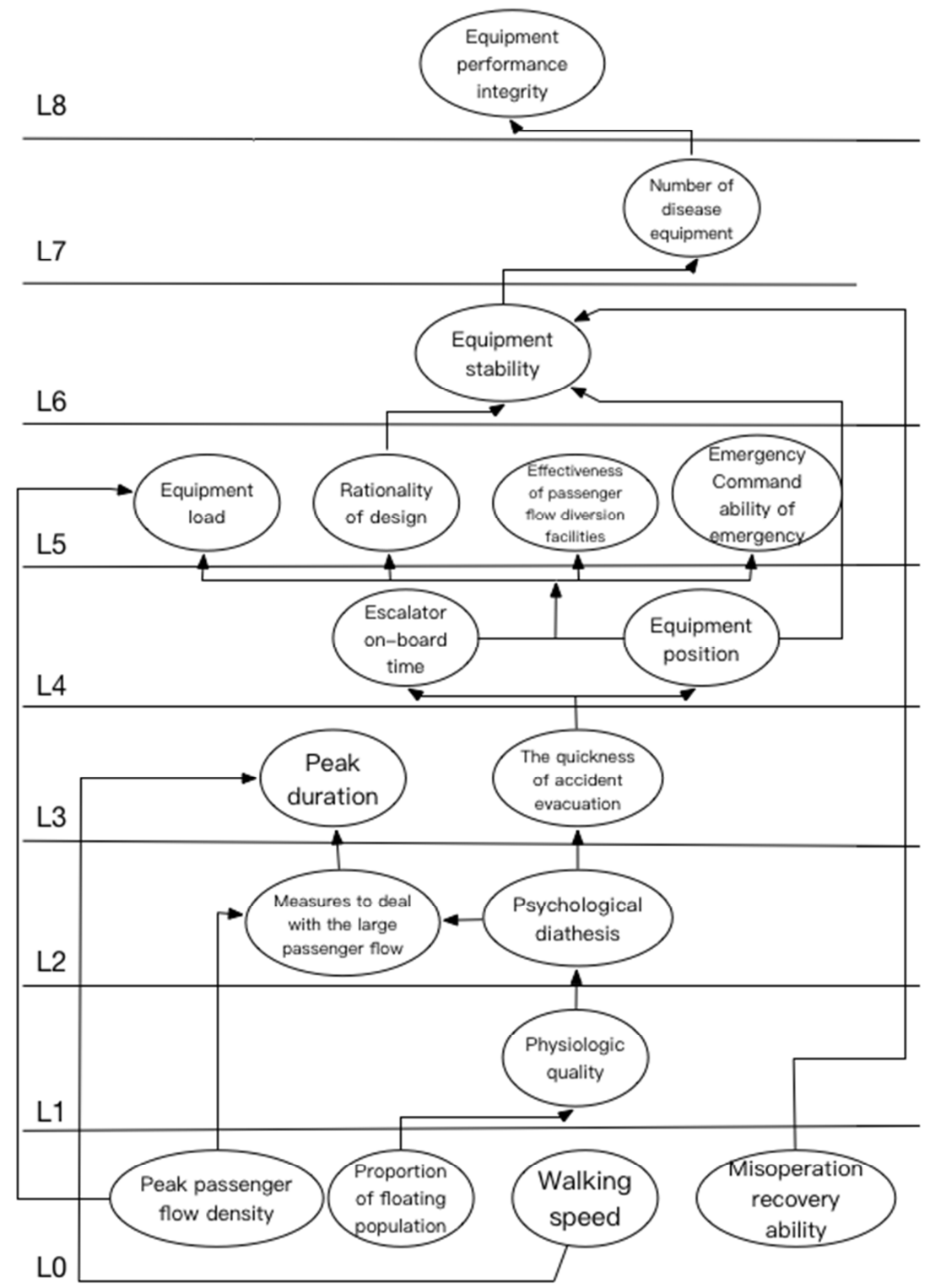

Figure 1. ISM skeleton map of subway crowded stampede. 
The complex links between the elements are seen in Figure 1 , and the 18 factors are divided into 4 nine-levels. Level 1 is the most important factor that affects the vulnerability of subway crowded stampede. Type I factors is the human factor, reflecting that people are important disaster-bearing bodies and direct victims of stampede in the subway. The impact of accidents on people is destructive, and it is the result of the interaction between human and accident vulnerability; Class II is the factor of equipment, the external factor that affects the vulnerability of subway, and is closely related to the first factor and is the auxiliary factor of human vulnerability analysis; Class III factor is the environmental factor, which is the dependence point of the subway vulnerability and is the "hard support" of the subway vulnerability analysis; Class IV factor is the management factor, which is the guarantee of the vulnerability of the subway. The first level factors are the peak intensity, the proportion of floating population, the speed of walking and the disoperation recovery ability. It directly affects the equipment load, physiological quality, equipment performance integrity and equipment stability and peak duration; The second level is the physiological quality, and the physiological quality can affect the psychological quality; The third level is psychological quality and effectiveness of large passenger flow response measures, psychological quality affects the speed of evacuation and the effectiveness of large passenger flow response measures, and the effectiveness of large passenger flow response measures will have an impact on the peak duration; The fourth level is the peak duration and the speed of evacuation of the incident, which will affect the location of the equipment and the time it takes for the elevator to ride; The fifth level is the time taken by the elevator and the location of the equipment, both of which have an impact on equipment loading, design rationality, passenger flow diversion measures and emergency command capabilities of emergencies, and the location of the equipment will have an impact on the stability of the equipment alone; The design rationality of the sixth level will affect the stability of the equipment; The seventh level is the stability factor of the equipment. The stability of the equipment will affect the number of the sick equipment; The eighth level is the quantity elements of the disease equipment, and the number of the disease equipment affects the integrity of the equipment. These four categories of 9 factors correlate with each other, promote each other, constitute the deportation structure relationship between the vulnerability of the effect on the subway, provide a logical way for subway safety management and risk management decision.

\section{Subway Crowded Stampede Vulnerability Risk Data Analysis}

The load bearing individual of occurrence of crowded stampede is the human being, the accident itself is caused by the interaction of many factors such as environment, individual, population density, flow of people and so on.
Therefore, the "degree of pedestrian congestion" is cited here as a reflection of various parts of the subway, such as corridor, stair lift, transfer platform and pedestrian aggregation index, this provides data support in quantitative calculate of passengers' possibility of a stampede in the process of movement, defines the critical value of different congestion states for reducing the probability of crowded stampede in vulnerable areas in order to timely alert the abnormal status in subway stations, prevent the occurrence of crowded stampede, make the passive control into active warning.

\subsection{Data Acquisition}

\subsubsection{Test Purpose}

Gather the characteristic parameters of crowd movement in subway station, such as speed, flow, density and so on.

\subsubsection{Test Time}

Clear day, morning peak(6:30-8:30).

\subsubsection{Test Place}

Due to the need to measure the degree of congestion, Xizhimen Station, Xierqi Station, Xidan Station, Liuliqiao Station and Guomao Station are chosen as the test location.

\subsubsection{Test time}

March 28, March 29th, March 30th, April, 2016, morning peak: 17:00-19:00.

\subsubsection{Test Content}

During the late peak of Xizhimen, Xidan, Liuliqiao, Guomao and Xierqi subway stations, pedestrians will be transferred from Line 13 to Line 2, Line 1 to Line 4 and Line 9 to Line 10, Line 1 to Line 10 and Changping Line to Line 13 to collect space occupancy rate, flow rate, speed and density data at stair escalators and to analyze the relationship between the four data sets.

\subsubsection{Acquisition Method}

In order to obtain accurate data characteristics of pedestrians, video data survey method and artificial detection method is used in this paper investigation, video data research has the advantages of long detection time, convenient maintenance, many parameters that can be detected, etc., but it is more difficult to process the data. So the video data is chosen to reprocess with the manual detection method. Compared with the video data survey method, the manual detection method is more convenient, economical and practical. However, it takes a lot of manpower and material resources, is time-consuming and labor-intensive and is not suitable for long-term data collection.

\subsection{Data Processing}

\subsubsection{Density}

Pedestrian density refers to the average number of pedestrians in a unit area (within the study area) on a transfer staircase or escalator, the unit isplm ${ }^{2}$. The method of calculating pedestrian density is to calculate the total $\mathrm{N}$ of 
pedestrians who remain in the survey area at the end of the time. By dividing the area of the survey area, the pedestrian density value can be get. The formula (1) is as follows: [10]

$$
\mathrm{M}=\frac{N}{|S|}=\frac{N}{L * W}
$$

$M$ represents the pedestrian density of the transfer to a staircase or escalator, the unit is $\mathrm{plm}^{2}, \mathrm{~N}$ is the number of pedestrians at the escalators on transferring to the stairs at a time, the unit is $\rho, \mathrm{S}$ is the area of area, the unit is $\mathrm{m}^{2}, \mathrm{~L}$ is the facility length, $\mathrm{W}$ is the facility length, the units are $\mathrm{m}$.

Because this method does not consider the observation area, the observation time interval and the number of consecutive observations, so if the observation area is different, it has a great influence on the density, in addition to considering the influence of the area of accuracy caused by the density, solve the relationship between velocity and density of the fine structure, it is referred to the Voronoi Method proposed by A. Seyfried and B. Steffen in 2010 to collect density data, formula is as shown in formula (2) and (3) below.

$$
\begin{gathered}
M_{V}=\frac{\left.\int{ }_{S} p \underset{x}{(\vec{x}}\right) d \vec{x}}{|S|} \\
M_{V^{\prime}}=\frac{N}{\sum_{i=1}^{N}|S|}
\end{gathered}
$$

In the formula, $\mathrm{p}_{i}(\underset{x}{\vec{x}})=\left\{\begin{array}{c}\frac{1}{S_{i}}, \underset{x}{\rightarrow} \in S_{i} \\ 0, \text { otherwise }\end{array}\right.$ and $\mathrm{p}(\vec{x})=\sum_{i} p_{i}(\vec{x})$.

The $\mathrm{M}_{\mathrm{v}}$ measurement is suitable for the smaller number of observations in the observation area, it requires all effective ThyssenKrupp polygon cells fall within the area of the measuring area. While $\mathrm{M}_{\mathrm{y}}$ can allow the Tyson polygonal cell to fall outside the area of the measurement area. So $\mathrm{M}_{\mathrm{v}}$ is more likely to be affected by adjacent edge polygons than $\mathrm{M}_{\mathrm{v}^{\mathrm{s}}}$.

\subsubsection{Speed}

Speed refers to the rate of people moving in the specified direction, which can be used to describe a movement or a static flow of people. The unit is $\mathrm{m} / \mathrm{s}$ or $\mathrm{m} / \mathrm{min}$. According to the average pedestrian walking speed of $22.5 \mathrm{~m} / \mathrm{min}, 60.7 \%$ of the total number of pedestrians is in the $60-80 \mathrm{~m} / \mathrm{min}$ speed range. The speed is affected by the pedestrian's age, gender, status, purpose and so on. The speed of men is generally higher than that of women. The speed of pedestrians is the highest among middle-aged men and young men, the second is the speed of young women, the lowest is the old women, and the speed of children is the most unstable. The individual pedestrian speed was generally higher than the group pedestrian speed.

In the speed processing, according to the video data of the video, the video is segmented into 25 frames per second, video processing by frame playback, while recording the given video distance pedestrians from entering the observation area to leave observation area accurate time node $\left(t_{1}, t_{2}\right)$, then calculate the velocity of pedestrians according to the length of the observation area, calculation formula as shown in formula (4): [11]

$$
\vec{v}_{\Delta x, i}(t)=\frac{\vec{x}_{i}\left(t_{2}\right)-\vec{x}_{i}\left(t_{1}\right)}{t_{2}-t_{1}}, \mathrm{t} \in\left[t_{1}, t_{2}\right]
$$

$\mathrm{V}_{\mathrm{i}}(\mathrm{t})$ represents the instantaneous velocity at the time of $\mathrm{t}$.

\subsubsection{Flow}

Flow refers to the number of pedestrians crossing a certain point or cross-sectional area within a unit of time, the unit is $\mathrm{p} /\left(\mathrm{m}^{*} \mathrm{~min}\right)$, here it is taken that the number of people passing the vertical cross-section per unit width in 1 minute. According to the basic principle of flow, the pedestrian flow is calculated to be $\mathrm{Q}(\mathrm{x}, \mathrm{y}, \mathrm{t})=\mathrm{M}(\mathrm{x}, \mathrm{y}, \mathrm{t}) * \mathrm{~V}(\mathrm{x}, \mathrm{y}, \mathrm{t}), \mathrm{M}$ and $\mathrm{V}$ have been given in the previous article. In the actual operation, the number of pedestrians passing through the section is counted for a time interval and unit width (in this case $1 \mathrm{~m}$ width) through studying the survey section of the target area.

\subsection{Data Analysis Results}

The relationship between the occupancy rate, flow rate, speed and density of stair escalators when the passer by changes from Metro Line 13 to line 2, line 1 to line 4, line 9 to line 10, line 1 to line 10, and Changping line to line 13 in

\begin{tabular}{|c|c|c|c|c|}
\hline & Xizhimen station & & & \\
\hline \multirow{2}{*}{ Parts } & \multirow{2}{*}{ Survey location } & Data on flows & Speed data & \multirow{2}{*}{ Density data } \\
\hline & & Direction/average flow (person/hour) & Category /average flow $(\mathrm{m} / \mathrm{s})$ & \\
\hline \multirow{2}{*}{ Stairs } & \multirow{2}{*}{ Line 13 -Line 2} & get on/1135 & get on $/ 0.590$ & 1.373 \\
\hline & & get off/349 & get off $/ 0.699$ & 2.386 \\
\hline \multirow{2}{*}{ Escalator } & \multirow{2}{*}{ Line 13 -Line 2} & get on/2685 & enter $/ 0.458$ & 1.583 \\
\hline & & get off/567 & out $/ 0.868$ & 1.757 \\
\hline \multirow{2}{*}{ Parts } & \multirow{2}{*}{ Survey location } & Data on flows & Speed data & \multirow{2}{*}{ Density data } \\
\hline & & Direction/average flow (person/hour) & Category /average flow (m/s) & \\
\hline \multirow{2}{*}{ Stairs } & \multirow{2}{*}{ Line 1-Line 10} & get on $/ 2700$ & get on $/ 0.577$ & 1.423 \\
\hline & & get off $/ 4830$ & get off $/ 0.712$ & 2.369 \\
\hline \multirow{2}{*}{ Escalator } & \multirow{2}{*}{ Line 1-Line 10} & get on $/ 3100$ & enter $/ 0.473$ & 1.564 \\
\hline & & get off $/ 6358$ & out $/ 0.885$ & 1.675 \\
\hline
\end{tabular}
Xizhimen, Xidan, Liuliqiao, Guomao and Xierqi thesefive stations during the late peak is shown in Table 3.

Table 3. The analysis table of the flow statistics of the transfer staircase and the escalator. 


\begin{tabular}{|c|c|c|c|c|}
\hline & Liuliqiao station & & & \\
\hline \multirow{2}{*}{ Parts } & \multirow{2}{*}{ Survey location } & Data on flows & Speed data & \multirow{2}{*}{ Density data } \\
\hline & & Direction/average flow (person/hour) & Category /average flow $(\mathrm{m} / \mathrm{s})$ & \\
\hline \multirow{2}{*}{ Stairs } & \multirow{2}{*}{ Line9-Line10 } & get on/705 & get on $/ 0.645$ & 1.435 \\
\hline & & get off $/ 3859$ & get off/0.732 & 2.412 \\
\hline \multirow{2}{*}{ Escalator } & \multirow{2}{*}{ Line9-Line10 } & get on/1124 & enter/0.425 & 1.596 \\
\hline & & get on/5364 & out $/ 0.815$ & 1.698 \\
\hline Guomao station & Xidan station & & & \\
\hline \multirow{2}{*}{ Parts } & \multirow{2}{*}{ Survey location } & Data on flows & Speed data & \multirow{2}{*}{ Density data } \\
\hline & & Direction/average flow (person/hour) & Category /average flow $(\mathrm{m} / \mathrm{s})$ & \\
\hline \multirow{2}{*}{ Stairs } & \multirow{2}{*}{ Line 1-Line 4} & get on $/ 1705$ & get on $/ 0.585$ & 1.385 \\
\hline & & get off $/ 3405$ & get off $/ 0.679$ & 2.409 \\
\hline \multirow{2}{*}{ Escalator } & \multirow{2}{*}{ Line 1-Line 4} & get on $/ 3931$ & enter $/ 0.475$ & 1.594 \\
\hline & & get off $/ 4366$ & out $/ 0.847$ & 1.749 \\
\hline & \multicolumn{3}{|l|}{ Xierqi station } & \\
\hline \multirow[t]{2}{*}{ Parts } & \multirow[t]{2}{*}{ Survey location } & Data on flows & Speed data & Density data \\
\hline & & Direction/average flow (person/hour) & Category /average flow $(\mathrm{m} / \mathrm{s})$ & \\
\hline \multirow[t]{2}{*}{ Stairs } & \multirow[t]{2}{*}{ Changping line-Line 13} & get on/11846 & get on $/ 0.536$ & 1.336 \\
\hline & & get off $/ 3758$ & get off $/ 0.644$ & 2.377 \\
\hline \multirow[t]{2}{*}{ Escalator } & \multirow[t]{2}{*}{ Changping line-Line 13} & get on/ 15956 & enter $/ 0.453$ & 1.436 \\
\hline & & get off $/ 2074$ & out $/ 0.868$ & 1.574 \\
\hline
\end{tabular}

\subsection{Data correlation Analysis}

According to the measured data of population characteristics in 5 subway stations, the data were integrated and the data of the unrelated points are removed, and Matlab is used for drawing. The scatter plot of the data about the relationship between population density-velocity and population density-flow of 5 subway stations in the staircase and the escalator is gotten. The scatter plots are shown in figures 2 and 3.

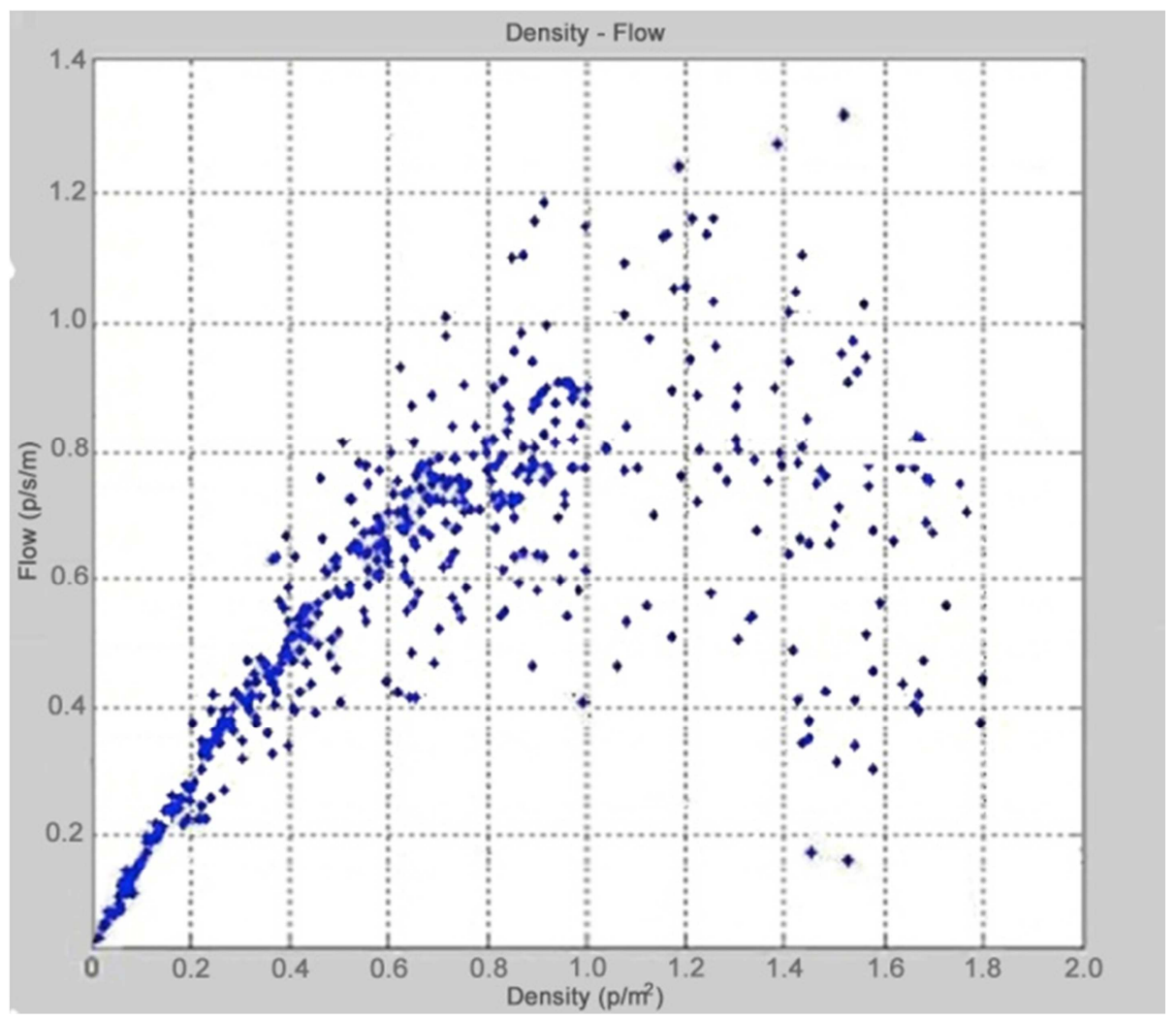

Figure 2. Density - speed relationship scatter plot. 


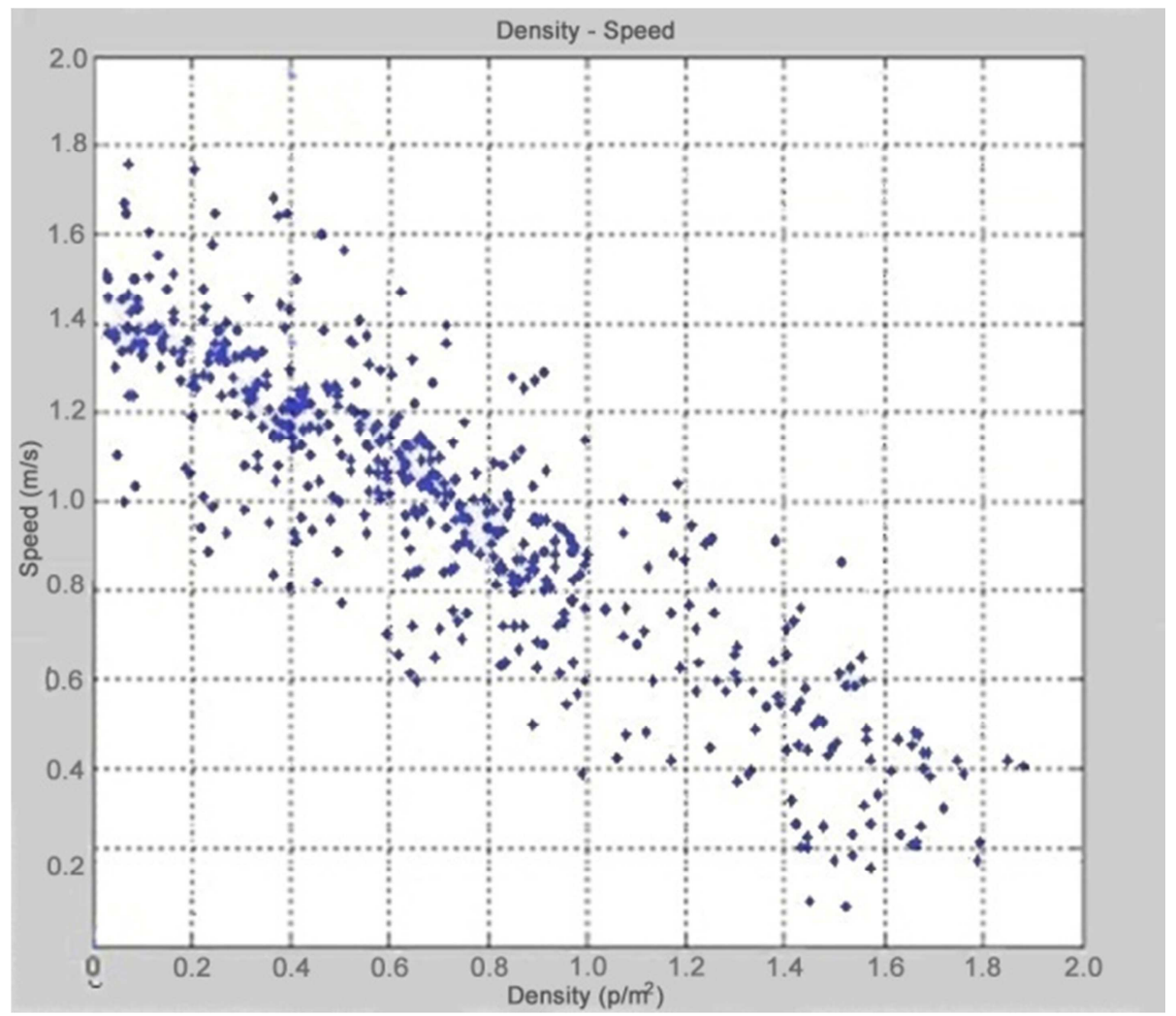

Figure 3. Density - flow relationship scatter plot.

Analysis of the relationship between population density, velocity and flow, as shown in Table 4:

Table 4. Analysis of the relationship between population density, velocity and flow.

\begin{tabular}{|c|c|c|c|c|c|c|c|c|c|}
\hline \multicolumn{10}{|c|}{ Dependent variable speed $(\mathrm{m} / \mathrm{s})$ Model summary and parameter estimates } \\
\hline \multirow[t]{2}{*}{ Equation } & \multicolumn{5}{|c|}{ Model summary } & \multicolumn{4}{|c|}{ Parameter estimation } \\
\hline & $\mathrm{R}^{2}$ & $\mathrm{~F}$ & df1 & df2 & Sig & \multicolumn{2}{|c|}{ Constant } & \multicolumn{2}{|l|}{ b1 } \\
\hline Linear & 0.873 & 6439.328 & 1 & 938 & 0.000 & \multicolumn{2}{|l|}{1.667} & \multicolumn{2}{|c|}{-0.503} \\
\hline Increase & 0.789 & 3503.635 & 1 & 938 & 0.000 & 0.710 & & -0.50 & \\
\hline \multicolumn{10}{|c|}{ Dependent variable:flow $(\mathrm{p} / \mathrm{s} / \mathrm{m})$ model summarizes and describes the estimates } \\
\hline \multirow[t]{2}{*}{ Equation } & \multicolumn{5}{|c|}{ Model summarizes } & \multicolumn{4}{|c|}{ Parameter estimation } \\
\hline & $\mathrm{R}^{2}$ & $\mathrm{~F}$ & df1 & df2 & Sig & Constant & b1 & b2 & b3 \\
\hline Cubed & 0.802 & 1263.347 & 3 & 936 & 0.000 & -0.013 & 1.752 & -580 & 0.018 \\
\hline
\end{tabular}

Based on the results of the estimated value, the relation between the density of the stairs and the speed function is obtained as shown in formula (5):

$$
\mathrm{V}=-0.506 * \mathrm{M}+1.667\left(\mathrm{R}^{2}=0.873\right)
$$

The formula of the relation between density and flow function is shown in formula (6).

$$
\mathrm{Q}=-0.018 * \mathrm{M}^{3}+(-0.580) * \mathrm{M}^{2}+1.752 * \mathrm{M}+(-0.013)\left(\mathrm{R}^{2}=0.802\right)(6)
$$

According to the relationship and scatter plot analysis shows: In the staircase and the escalator, the density and speed conform to a linear function. When the pedestrian density is $\mathrm{M}$ $<1.14\left(\mathrm{p} / \mathrm{m}^{2}\right)$, the pedestrian average speed in the hub is relatively free, and the pedestrian speed distribution is more dispersed and it decreases with the density increasing. When the pedestrian density is $1.14\left(\mathrm{p} / \mathrm{m}^{2}\right)<\mathrm{M}<2.07\left(\mathrm{p} / \mathrm{m}^{2}\right)$, the velocity distribution of pedestrians is concentrated, the range of velocity fluctuation is $0.59(\mathrm{~m} / \mathrm{s}) \sim 0.72(\mathrm{~m} / \mathrm{s})$, and it still continues to decrease with the increase of density. When the pedestrian density is $M>2.07 \mathrm{p} / \mathrm{m}^{2}$. The average speed of pedestrians in the hub is changed from a free-flow state to a non-free state, that is, a crowded state, and continues to decrease as the density increases, until the crowded state of waiting is reached.

In the staircase and the escalator, the density and flow are in the form of cubic equation with one unknown. When the pedestrian density is $\mathrm{M}<1.14(\mathrm{p} / \mathrm{m} 2)$, the pedestrian flow in the hub is small, and the crowding behavior is not formed temporarily, and the pedestrian flow increases with the increase of pedestrian density. When the pedestrian density is $1.14\left(\mathrm{p} / \mathrm{m}^{2}\right)<\mathrm{M}<2.07\left(\mathrm{p} / \mathrm{m}^{2}\right)$, the pedestrian flow in the hub gradually increases, and its crowding behavior begins to gradually form. The flow mainly concentrates between 72 $(\mathrm{p} / \mathrm{min} / \mathrm{m}) \sim 75(\mathrm{p} / \mathrm{min} / \mathrm{m})$, and the pedestrian flow decreased with the increase of pedestrian density. 


\section{Vulnerability Risk Early Warning Analysis of Subway Crowded Stampede}

\subsection{Construct the Risk Matrix of Crowded Stampede}

Based on the related data analysis of visitors flow rate, pedestrian flow speed and pedestrian flow density, taking the basic data density $(\mathrm{M})$ as the observation value, and the accident probability, economic loss and casualty situation are listed adjudging criteria. The risk matrix is established to conduct a qualitative and quantitative analysis of the risk of crowded stampede in the subway station in order to achieve precise control. The risk matrix is shown in Table 5.

Table 5. Risk matrix of subway crowded stampede.

\begin{tabular}{|c|c|c|c|c|c|c|c|c|c|}
\hline & Risk & Medium & High Risk & Extremely High & Valid & Value & \multicolumn{3}{|c|}{ Possible Loss } \\
\hline & Matrix & Risk(Level III) & (Level IV) & Risk(Level V) & Categories & value & \multicolumn{3}{|c|}{ Degree of Casualty } \\
\hline \multirow{4}{*}{$\begin{array}{l}\text { Common } \\
\text { Risk } \\
\text { (Level II) }\end{array}$} & 6 & 12 & 18 & 24 & 30 & A & 6 & \multicolumn{2}{|l|}{ Multiple Deaths } \\
\hline & 5 & 10 & 15 & 20 & 25 & B & 5 & \multicolumn{2}{|l|}{ One person death } \\
\hline & 4 & 8 & 12 & 16 & 20 & $\mathrm{C}$ & 4 & \multicolumn{2}{|c|}{ Multiple Serious Injuries } \\
\hline & 3 & 6 & 9 & 12 & 15 & $\mathrm{D}$ & 3 & \multicolumn{2}{|c|}{ One person Serious Injury } \\
\hline \multirow{6}{*}{$\begin{array}{l}\text { Low Risk } \\
\text { (Level I) }\end{array}$} & 2 & 4 & 6 & 8 & 10 & $\mathrm{E}$ & 2 & \multicolumn{2}{|c|}{ Multiple minor Injuries } \\
\hline & 1 & 2 & 3 & 4 & 5 & $\mathrm{~F}$ & 1 & \multicolumn{2}{|c|}{ One person Minor Injury } \\
\hline & $\mathrm{K}$ & $\mathrm{J}$ & I & $\mathrm{H}$ & G & $\begin{array}{l}\text { Valid } \\
\text { Categories }\end{array}$ & $\begin{array}{l}\text { Risk } \\
\text { value }\end{array}$ & Risk level & Memo \\
\hline & & & $\begin{array}{l}1.14<\mathrm{M}<2.07 \\
\text { Happened }\end{array}$ & & & Possibility & $>25$ & $\begin{array}{l}\text { Extremely High } \\
\text { Risk }\end{array}$ & Level V \\
\hline & $\begin{array}{l}\text { Never } \\
\text { happened }\end{array}$ & $\begin{array}{l}\text { Happened Once } \\
\text { over } 5 \text { years }\end{array}$ & $\begin{array}{l}\text { Once within } 5 \\
\text { years }\end{array}$ & $\begin{array}{l}\text { Happened Once } \\
\text { within } 2 \text { years }\end{array}$ & $\begin{array}{l}\text { Once per } \\
\text { year }\end{array}$ & Frequency & $18 \sim 25$ & High Risk & Level IV \\
\hline & Excellent & $\begin{array}{l}\text { Great, Hardly } \\
\text { breakdown }\end{array}$ & $\begin{array}{l}\text { Years later may } \\
\text { breakdown }\end{array}$ & $\begin{array}{l}\text { Close to expire } \\
\text { occasionally } \\
\text { breakdown }\end{array}$ & $\begin{array}{l}\text { Out of date } \\
\text { Always } \\
\text { breakdown }\end{array}$ & $\begin{array}{l}\text { Equipment } \\
\text { Status }\end{array}$ & $\begin{array}{l}9 \sim 16 \\
3 \sim 8 \\
1 \sim 2\end{array}$ & $\begin{array}{l}\text { Medium Risk } \\
\text { Common Risk } \\
\text { Low Risk }\end{array}$ & $\begin{array}{l}\text { Level III } \\
\text { Level II } \\
\text { Level I }\end{array}$ \\
\hline
\end{tabular}

The density interval values $0-1.14,1.14-2.07$ and 2. 07-max is taking as the research samples. [12] Here the author stipulates that $0-1.14$ corresponds to "impossible" and "less likely" (median 0.57), $1.14<\mathrm{M}<2.07$ corresponds to the "occasional happened in the past" "it happened or happened in unusual circumstances in the past" (median 1.1), M> 2.07 corresponds to the possibility of "occurred in the expected situation", here the author makes some explanations for the classification of the risk:

(1) When the population density reaches $0<\mathrm{K}<1.14$, it does not mean that an accident will never occur. And in this population density, the population is in a free-flowing state. Under normal circumstances, it is hard for people to make physical contact and therefore there is no speed collision. The risk of an accident is low. One of the cornerstones of crowded stampede is "speed change". The change of speed means that a person or a region has a sudden change or collision in speed, and there is a theoretical peak value curve of speed change. Peak point represents the speed collision at this point, the kinetic energy of change caused by changes in speed makes people fall, so the occurrence of crowded stampede. Therefore, one of crowded stampede accident conditions is a certain crowd density. And without a certain amount of crowd density, crowded stampede cannot happen; the worst of events will only be "fall" or "collision."

(2) In view of the possibility of "occasionally occurring in the past" or "occurring in the past or occurring in exceptional circumstances", the author defines the population density as $1.14<\mathrm{K}<2.07$ because the free flow has been restricted under this population density. As crowds begin to become crowded, the probability of occurrence of a crowded stampede is raised when the condition of "sudden jump" is established. In this density interval, there is more human-to-human contact, and as the density increases, contact rate increased, the risk then increased.

(3) When $M>2.07$, the crowd free flow characteristics completely disappeared, in a state of congestion. In this state, once a sudden event occurs, such as fainting, quarrel, shouting, violent incidents, terrorist acts, someone falls, etc., will directly or indirectly lead to the occurrence of crowded stampede, so when the flow of people at a density of $\mathrm{M}>2.07$, the risk of a stampede is "as expected".

\subsection{Crowded Subway Accident Risk Warning Stampede Control}

The risk of crowded stampede in the subway station is divided into four levels, level I includes low risk and general risk, namely the risk value is $1 \sim 2$ or 3 8; Level II is medium risk, the risk value is 9 16; Level III is Significant risk 18 25; Level IV is particularly significant risk, the value of risk at this time is greater than 25 . The calculation of the risk value is based on the possible situation and the consequences. It is proposed to automatically identify the human traffic by setting up a video facial analysis device above the key crossings and to determine the traffic density by the traffic and video surveillance area, so as to obtain the real-time traffic density. According to the value and possible accident results, the start emergency plan to prevent the occurrence of crowded stampede is determined.

Depending on the level of risk, the subway station staffs need to implement different interventions according to instructions, and four kinds of warning control measures 
according to the different divisions of the level of risk:

Level I (blue): At this level of risk, the probability of an accident occurring is very low and unlikely or less likely. Therefore, when the data processing center obtains the density data and the real-time situation analysis detected by the detectors of stairways and escalators, the accident risk of level I am determined. The following interventions can be implemented: Personnel: Inform staff of station to check whether the normal setting of diversion facilities at stairwell and escalator entrance are correct; the staff inside station and platform staff remind passengers to pay attention to safety through public address facilities. Facilities: Adjust the speed of escalators from the control center, slightly increase the speed of escalators and increase the carrying capacity.

Level II (yellow): At this risk level, the probability of an accident increases and the density of people starts to change from a free flow to a turbulent flow so that the contact rate between passengers increases. When it is determined that the accident risk is level II, the following interventions need to be implemented in addition to the implementation of Level I measures. Personnel: security personnel artificial restriction, reduce the density of passenger stations, reduce the contact rate between passengers; increase in the escalators and stairway crossing monitoring evacuation site staff. Equipment: reduce the elevator operating speed from the control center (at this time the population density increases, the movement speed in the elevator port is lower, in order to reduce the peak collision speed, thus reducing the elevator speed, passengers smooth transition from the platform to the elevator). Increase the elevator stairs crossing diversion facilities.

Level III (orange): In this class, in addition to taking level I and level II measures, the following measures need to be taken. Personnel measures: In the subway station to carry out diversion current limiting measures to reduce the station traffic; in the staircases and escalators and platforms to increase the staff to guide the evacuation. Equipment: Open the station within the current limit, to increase the station can move area. Management: Into the orange warning period, the rail transport operators and other relevant member units should immediately start the relevant special plan to strengthen information monitoring and collection. Related inspections of rail transit operators focus on the hidden parts of the investigation. Professional emergency rescue teams stand by at all times and receive promptly after receiving the orders, and take corresponding measures to prevent the occurrence of the incident or the further expansion of the situation as the case may be.

Level IV (red): Based on the orange warning response, the Emergency Leading Group Office shall timely keep information and report to the Emergency Leading Group to start the plan. The Emergency Leading Group promptly conducts the judgment. If the red warning is reached, it will start the plan and deploy the related early warning and response work. All the inspectors will be on the job and the entire area will be inspected one by one. The orbital traffic will be suspended when necessary. At the same time to strengthen the ground bus capacity.

\section{Conclusions}

In this paper, the crowded stampede of subway in China is calculated and analyzed in the recent ten years, and used the ISM and MATLAB and SPSS to analyze the actual data of the five metro stations in Beijing and obtained the following conclusions.

(1) In view of the huge passenger flow pressure of the subway at present, each station presents different degrees of vulnerability, but the overall vulnerability shows a certain degree of similarity. Based on the research on the concept and mechanism of the fragile and vulnerable parts of the subway stampede and by referring to the accident cause theory, this paper analyzes the correlation between the vulnerable parts and the fragility from the aspects of personnel, equipment, environment and management, with the explanation of the structural model, And finally got the relationship diagram of nine levels, which can provide some references for the safe operation of the subway and the formulation of the emergency management plan.

(2) According to the actual measured value of crowd's characteristic attribute in subway station, using regression analysis of MATLAB and SPSS, the relationship between the density of crowd escalator at the entrance of escalator in subway station and the speed of people flow is obtained, The interval value of the population density conditions necessary for the crowded stampede in the subway station is analyzed to provide sample values for the data monitoring of the stairways and escalators in the subway station.

(3) Using the quantitative data of the vulnerable parts and the statistical data of the subway accidents, the risk matrix model of the subway congestion stampede is constructed to provide a technical reference for the prevention of the crowded stampede in the subway and determine the four warning risk levels of I, II, III and IV Form conditions and early warning measures.

In this study, the key risk parts of some stations in Beijing Subway are selected to study the vulnerability and the vulnerability analysis did not proceed in a large scale. The accuracy of the analysis process needs to be further verified. The experimental population density data also need to be compared with the actual congestion stampede accident data for comparison.

\section{Acknowledgements}

This paper is supported by 'Key Technology Projects for the Prevention and Control of Serious Accidents in Safety Production' (Beijing-0001-2017AQ), National Administration for Work Safety of People Republic of China.

\section{References}

[1] XU Tian-kun. Study on Risk Assessment Theory and Methods on Urban Rail Transit Network Operation [D]. Beijing: Beijing Jiaotong University, 2012. 
[2] Yamada Y, Takatori T, Nagao M, Iwase H, Kuroda N, Yanagida J, Shinozuka T. Expression of paraoxonase is form did not confer protection from acute sarin poisoning in the Tokyo subway terrorist attack [J]. International Journal of Legal Medicine (Print), 2001, 1152.

[3] Wagner U, Fälker A, Wenzel V. [Fatal incidents by crowd crush during mass events: (Un)preventable phenomenon] [J]. Der Anaesthesist, 2013, 621.

[4] Wang qiquan. safety assessment [M]. Beijing: Chemical Industry Press, 2015:78-81.

[5] Zhang qingsong. The risk theory of crowd stampede and its application in sports competition [D]. Nankai University, 2007.

[6] Wang qiquan. Study on accident risk of subway stampede based on weighted relation degree algorithm [J]. China Safety Science Journal, 2013, 05:94-100.

[7] Liu yan, Wangtong, Dinghui, Wuzhongzi. DEA Model Study on Accident Risk Assessment of subway station crowded stampede [J]. China Safety Science Journal, 2013, 10:100-104.
[8] Wang qiquan, Wang weixian. Planning and counter measures of emergency evacuation route in subway fire [J]. Journal of Safety Science and Technology, 2017, 03:131-136.

[9] Wang shuliang. Vulnerability Analysis of Infrastructure System Based on Complex Network Theory [D]. HUST, 2013.

[10] Wang qiquan, Wu jiaxin, Designing a linkage system for response to subway stampede accidents based on STAMP model [J]. China Safety Science Journal, 2016, 12:158-162.

[11] Wang qiquan. The risk theory of crowd stampede [M]. Beijing: China meteorological Press, 2017:127-143.

[12] Wang qiquan, Wang weixian. Planning and counter measures of emergency evacuation route in subway fire [J]. Journal of Safety Science and Technology, 2017, 03:131-136. 